\title{
Comparative Study of Virtual Machine Migration Techniques and Challenges in Post Copy Live Virtual Machine Migration
}

\author{
Rajwinder Singh ${ }^{1}$, Dr. K. S. Kahlon ${ }^{2}$, Sarabjit Singh ${ }^{3}$ \\ ${ }^{1}$ PhD Scholar, Department of Computer Science, Guru Nanak Dev University, Amritsar, Punjab, India \\ ${ }^{2}$ Professor, Department of Computer Science, Guru Nanak Dev University, Amritsar, Punjab, India, \\ ${ }^{3}$ System Manager, Guru Nanak Dev University, Amritsar, Punjab, India
}

\begin{abstract}
Cloud computing is the emerging service provider used to manage computing resources like networks, storage, servers, applications and services which requires optimum effort of management [1]. Virtualization in cloud computing is gaining more importance today due to lack of proper utilization of resources, improper load balancing of processing nodes, lesser isolation of applications, extent of tolerating the faults in virtual machines, to increase the portability of nodes and to rise the efficiency of cost of the physical server. So, migration is one of the most important features of virtual machines technology [2]. Virtual machine migration is the migration of virtual machine from one physical host to another [1]. It is mainly done via two approaches pre copy migration and post copy migration. Pre copy migration first transfers the memory and then transfers the execution while post copy migration first transfers the execution and then transfers the memory [7].The main motive of this paper is to provide the better understanding of post copy virtual machine migration technique research challenges by comparing existing general \& network aware virtual machine migration techniques in cloud computing.
\end{abstract}

Keywords: Cloud Computing, virtual machine migration, pre copy, post copy, hypervisor.

\section{Introduction}

In recent years, the demand for Cloud computing is on the rise and it has become a focus in information technology arena. Cloud computing has been widely employed by the industry community, government bodies, business and also among academy and research community. Cloud computing is not a new concept in the era of IT, it provides the following facilities:

\subsection{Virtualization}

Virtualization methodology divides the computer resources into multiple executable virtual machines through hardware and software portioning [2]. It allows multiple virtual machines to run on a single physical machine. It permits less high powered servers to create more low powered servers, thus reduces overall cost in power, space and other infrastructure [7].

Hypervisor or virtual machine manager or virtual machine monitor is a program which enables multiple operating systems to be shared on a single host. Each operating system has a processor host and resources; hypervisor allocates needed resources to each operating system and ensures that guest operating system (also called virtual machine) cannot interrupt each other. Hypervisor is of two types [8]:

\section{1(a) Bare Metal Hypervisor}

Bare Metal Hypervisor is a hypervisor that itself is installed on the hardware and has a control over its available resources as no intermediary is required to access the resources.

Examples: HyperV, VMware

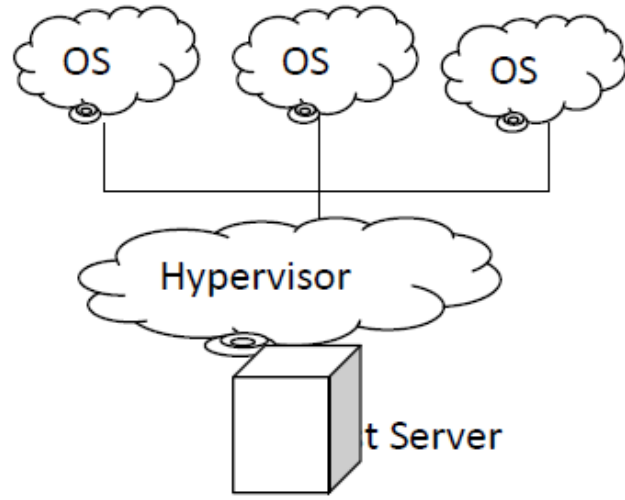

Figure1: Bare Metal Hypervisor

\section{1(b) Hosted Hypervisor}

Hosted hypervisor is a hypervisor that is installed in the operating system of a server and that operating system has a control over it. Example: VMware Player, Virtual Box, Xen

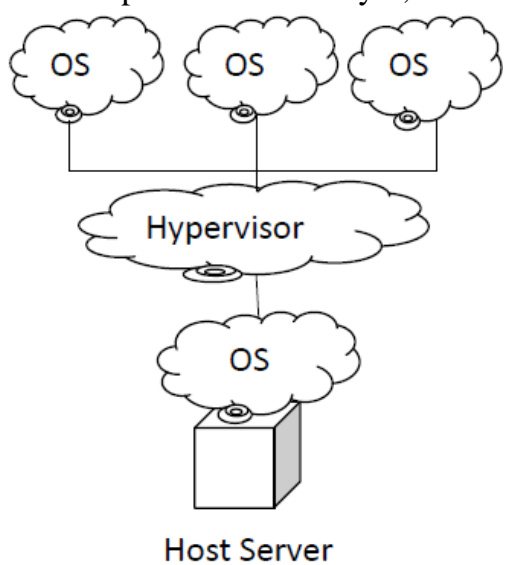

Figure 2: Hosted Hypervisor 


\section{International Journal of Science and Research (IJSR) \\ ISSN (Online): 2319-7064}

Index Copernicus Value (2013): 6.14 | Impact Factor (2014): 5.611

\section{Virtual Machine Migration}

Virtual machine migration is the migration of virtual machine from one physical host to another without disrupting the users [1]. It is categorized as:

(a) [8]Non-live or Off-line Virtual Machine Migration: In it, Virtual machine at the source host is paused and then transfer all states of source host to the target or destination host and then finally resume the working of virtual machine at the target host. The major drawback of it is that it results in larger down time.

(b) [8]Live Virtual Machine Migration: In it, Virtual machine is transferred from one host to another with minimum possible disruption of services. It has following performance metrics [3][4][6][10]:

(i) Preparation Time: Time between the migration process start and virtual machine's processor state is sent to the destination node, during which the virtual machine run continuously and creates page faults is called preparation time.

(ii) Resume Time: Time between the resuming of the virtual machine's running and migration end is called resume time. Note that, all dependencies are removed on the source host.

(iii) Pages transferred: The total amount of pages transferred including the copies of pages.

(iv) Down Time: Time during which the running of virtual machine is stopped. It contains sending of state of the processor.

(v) Total Migration Time: Time taken by the migration process; from the initiating of the migration process until end of the migration process. This time is important as it affects the resource releasing on both the source node and the destination node.

(vi) Application Degradation: When migration of virtual machine take place from on host to the other, the performance of the application is degraded which is executing at that virtual machine.

\subsection{Live Virtual Machine migration Techniques:}

\section{(i) Pre-Copy memory migration}

(a) Warm-up phase: In it, the hypervisor create duplicates of all memory pages from the source node and copies to the destination node but virtual machine is not halted at the source node. If some changes are there in the pages of source node during the process copying the duplicates, then data will be re-duplicated until the rate of reduplicating the data is less than the rate of copied page which does not contain the recent value i.e. the page being corrupted(dirty page) [2][10].

(b) Stop-and-Copy phase: In it, once the warm-up phase is over; the virtual machine is halted at the source host, the changed data left will be copied to the destination node and virtual machine start processing at the destination host [2][10].

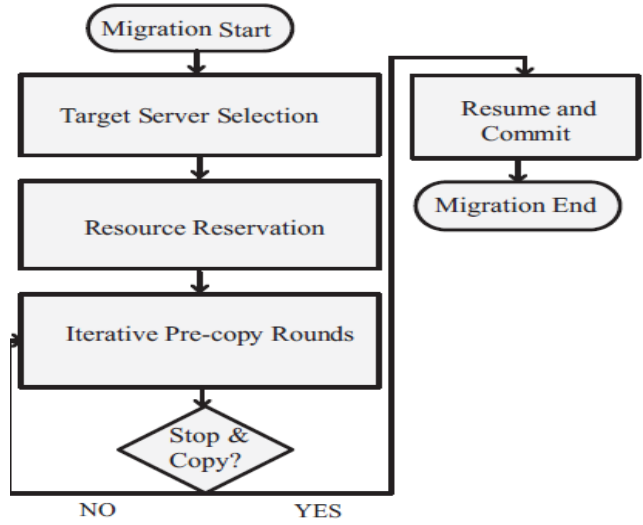

[13]Figure 3: Pre copy migration

(ii) Post copy memory migration

In it, virtual machine is firstly retired for some time at the source host; when it is suspended a small set of running state of virtual machine (CPU Registers) is sent to the destination host and virtual machine start its working at the destination node even though most of the memory state is yet residing on the destination host. At the destination host when virtual machine tries to fetch the pages which are not being sent; it will create page faults. The two said faults are trapped at the destination host and sent back to the source host over the network which will create network faults. The source host responds to these network faults by sending faulted pages. In this case, it can degrade the performance of the application running inside the virtual machine.

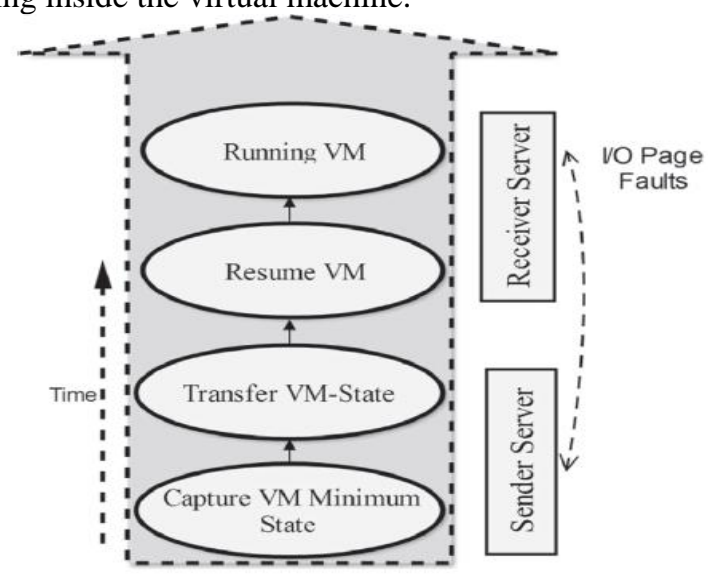

[13]Figure4: Post copy migration

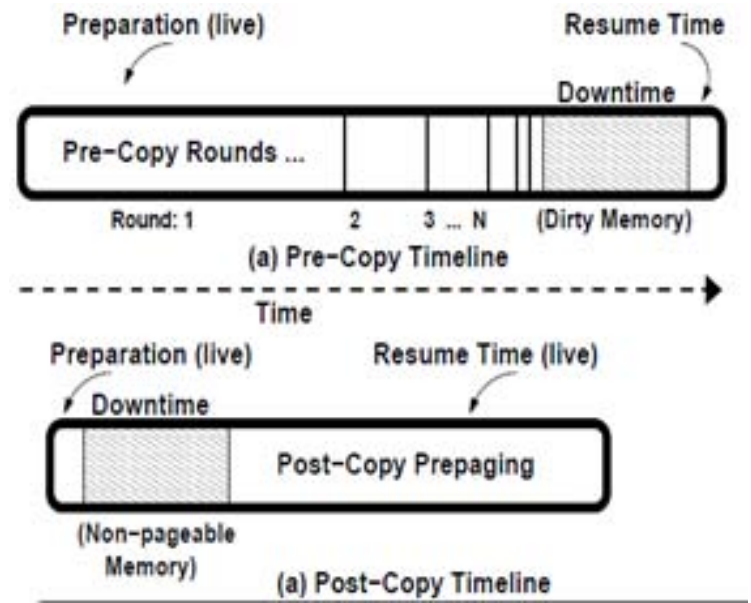

[13]Figure5: Timeline of Pre copy vs. Post copy migration 


\section{International Journal of Science and Research (IJSR) \\ ISSN (Online): 2319-7064}

Index Copernicus Value (2013): 6.14 | Impact Factor (2014): 5.611

(iii) Hybrid Virtual machine migration [9]

It is the combination of both pre copy and post copy virtual machine migration. It is based on five phases:

(a) Preparation Phase: System resources required at the target host are reserved.

(b) Bounded pre copy rounds Phase: Identify the delimited pre copy rounds and working set of virtual machine is transferred to the receiver server.

(c) Virtual Machine state transfer Phase: The minimum state of virtual machine is captured and sent to the receiver server to resume the virtual machine at the target host.

(d) Virtual machine resume Phase: At the receiver server, it launches the transferred state.

(e) On Demand paging Phase: On the basis of application, requests of read/write.

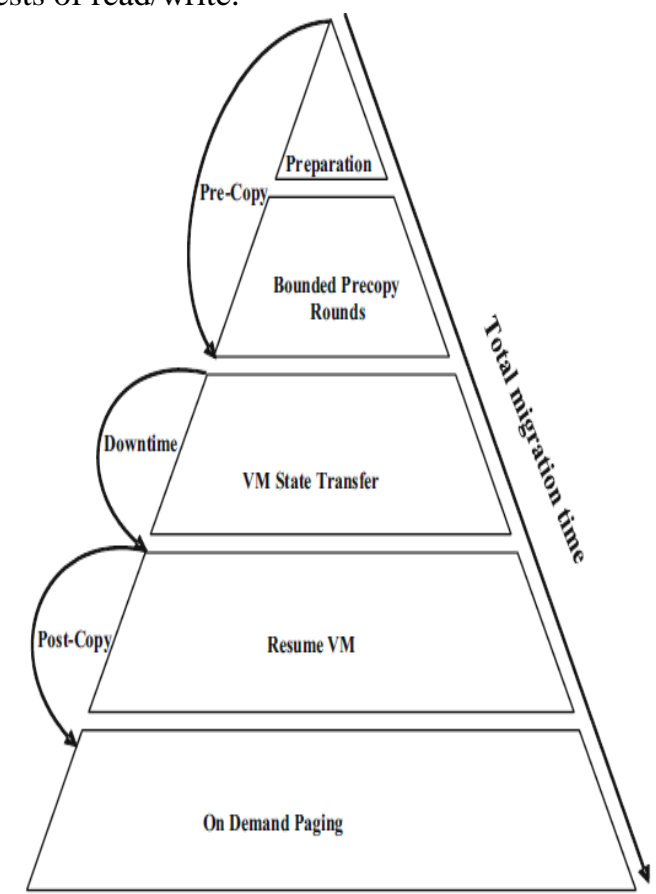

Figure 6: Hybrid Virtual Machine Migration

\subsection{Post Copy variations [10] [11]}

(1) Post Copy through demand paging: In it, the pages are transferred only once and it will result in page faults when requesting the referenced page from the source node over the network. As a result, it will slow down the processing of the virtual machine as it increases the length of the resume time and creates the dependencies in the form of an unfetched pages residing for unpredictable time periods.

(2) Post Copy through Active Pushing: To reduce the dependencies in the form of a unfetched pages residing for unpredictable time periods; one way is to initiatively "push" the pages on the destination node from the source node even though the virtual machine continues running at the destination node. Active Push evades the sending of pages which are faulted in the destination virtual machine. Thus, pages are sent only once either via demand paging or active push.

(3) Post copy through Pre Paging: It is impossible to know the exact fault tolerance behavior of pages but by estimating the faulting addresses to predict the spatial locality of virtual machine's memory access pattern, we can expect the occurrence of page faults in advance and accept the better page pushing sequence to access the patterns.

\subsection{Virtual machine Migration Applications [2][9][4]}

(i) Online maintenance: Virtual machine migration improves the reliability on system and availability of system and it upgrades and maintains the system without the halting of the system.

(ii) Load Balancing: To balance the workload between virtual machines, the load of heavily loaded or overloaded virtual machine is migrated to lightly loaded or under loaded virtual machine.

(iii) Energy management: The underutilized virtual machine servers are switched off to save the energy or efficiently use the power.

(iv) Resource Sharing: On starvation of resources, the resource hungry virtual machine is relocated to the resource rich virtual machine.

(v) Fault tolerance: Before the fault occurs in the virtual machine, a fault tolerant system triggers virtual machine migration.

(vi) Mobile computing: Virtual machine migration migrates the application running on system along with the operating system state from the desktop server to the mobile phones and vice-versa.

\section{Literature Review}

Qi Zhang and others [14] gives the explanation to topics related to computing. He provides a better understanding on the topic of cloud computing, its layered architecture, its business model, types of cloud and the terms related to cloud computing like virtualization, virtual machine migration, server consolidation, energy management, etc. and gives the direction towards the research challenges in cloud computing.

[2] says that VMM facilitates system administrator to migrate an OS instance of one physical node to another without the disturbance of services of host on the OS being migrating. VMM uses the resources of both the machines; the machine from which virtual machine is migrating and the machine to which it is being migrated. He reduces the size of data image on source host before migration according to the probability factor and threshold values.

Virtual machine migration was first proposed by Clark et al [13]. Virtual machine manager or hypervisor is a middleware between two physical nodes which facilitates abstraction from physical resources of one node to the other node. Through software emulation methods and virtualization of hardware systems, virtual machines are created. Virtual machines are acting as physical computers which have their own virtual RAM, Central Processing Unit, Network Interface Card and hard disk [12].

[10] says that Virtualization is a technique to run several operating systems simultaneously on one physical server, has become the core concepts in modern data centers. Virtual 


\section{International Journal of Science and Research (IJSR) \\ ISSN (Online): 2319-7064 \\ Index Copernicus Value (2013): 6.14 | Impact Factor (2014): 5.611}

machine migration (VMM) is a useful tool for administrator of data center and clusters. It allows clean separation between hardware and software.

[4] categorized the techniques which are used to minimize the downtime and consider the bandwidth which provides the better performance of virtual machine.

[3] gives the design, implementation and evaluation of Pre copy, Pre copy vs. Post copy, Full Post copy and Hybrid Post copy techniques that results in minimum page faults incurred.

[5] Hines explains the post copy via pre paging strategy through Bubbling with single pivot and multiple pivots.

[6] Michael gives the design and implementation of post copy approach through Dynamic Self Ballooning on Xen and Linux based platforms.

[7] explain various Network aware virtual machine migration techniques.

[8] gives the comparative analysis of various live virtual machine migration techniques.

[9] gives a detailed analysis, taxonomy, and research issues of virtual machine migration.

\section{Comparison of common Virtual Machine Migration Techniques [8]}

Table1.1: Comparative analysis of various virtual machine migration techniques

\begin{tabular}{|c|c|c|c|}
\hline $\begin{array}{l}\text { Virtual Machine } \\
\text { Migration } \\
\text { Technique }\end{array}$ & \multicolumn{3}{|c|}{ Method } \\
\hline Non-live migration & \multicolumn{3}{|c|}{$\begin{array}{l}\text { 1. Stop the source virtual machine. } \\
\text { 2. Copy all the pages to the destination host. } \\
\text { 3. Start executing virtual machine at } \\
\text { destination host }\end{array}$} \\
\hline Pre Copy approach & \multicolumn{3}{|c|}{$\begin{array}{l}\text { First transfer the memory and then transfer the } \\
\text { execution }\end{array}$} \\
\hline \multirow[b]{2}{*}{$\begin{array}{l}\text { Improved Pre Copy } \\
\text { approach }\end{array}$} & \begin{tabular}{c|} 
Memory \\
Compression \\
Technique \\
\end{tabular} & \begin{tabular}{|c|} 
Delta \\
Compression
\end{tabular} & $\begin{array}{l}\text { It is implemented } \\
\text { as a modified } \\
\text { KVM hypervisor }\end{array}$ \\
\hline & $\begin{array}{c}\text { Frequently } \\
\text { updated } \\
\text { memory pages }\end{array}$ & Page Bitmap & $\begin{array}{l}\text { *Judge the iteration } \\
\text { process. } \\
\text { *Put the frequently } \\
\text { updated pages into } \\
\text { page bitmap } \\
\text { *Transfer those } \\
\text { pages in the last } \\
\text { iteration round }\end{array}$ \\
\hline $\begin{array}{l}\text { Post copy } \\
\text { approach }\end{array}$ & \multicolumn{3}{|c|}{ First transfer the execution and then the memory } \\
\hline
\end{tabular}

Table1.2: Comparative analysis of various virtual machine migration techniques

\begin{tabular}{|c|c|c|}
\hline $\begin{array}{l}\text { Virtual Machine } \\
\text { Migration } \\
\text { Technique }\end{array}$ & Advantages & Disadvantages \\
\hline $\begin{array}{l}\text { Non-live } \\
\text { migration }\end{array}$ & $\begin{array}{c}\text { Simple Concept and easy to } \\
\text { implement }\end{array}$ & Down time is more \\
\hline $\begin{array}{l}\text { Pre Copy } \\
\text { approach }\end{array}$ & $\begin{array}{l}\text { 1. Down time }<1 \text { sec. } \\
\text { 2. On aborting migration, } \\
\text { system do not crash as } \\
\text { virtual machine is still } \\
\text { running on source host }\end{array}$ & $\begin{array}{l}\text { Overhead of } \\
\text { duplicate page } \\
\text { transmission }\end{array}$ \\
\hline \multirow[b]{2}{*}{$\begin{array}{l}\text { Improved Pre } \\
\text { Copy approach }\end{array}$} & $\begin{array}{l}\text { 1. Less Down time. } \\
\text { 2. Migration throughput is } \\
\text { increased }\end{array}$ & $\begin{array}{c}\text { Overhead of } \\
\text { Compression } \\
\text { technique }\end{array}$ \\
\hline & $\begin{array}{l}\text { 1. } 34 \% \text { total data transfer is } \\
\text { reduced. } \\
\text { 2. } 32.5 \% \text { total migration } \\
\text { time is reduced }\end{array}$ & $\begin{array}{l}\text { Not applicable to } \\
\text { wide area live } \\
\text { virtual machine } \\
\text { migration } \\
\end{array}$ \\
\hline $\begin{array}{l}\text { Post copy } \\
\text { approach }\end{array}$ & $\begin{array}{l}\text { 1. Memory page is } \\
\text { transferred at most once. } \\
\text { 2. Total migration time is } \\
\text { achieved as baseline }\end{array}$ & $\begin{array}{c}\text { More Down time } \\
\text { as compared to pre } \\
\text { copy }\end{array}$ \\
\hline
\end{tabular}

\section{Comparison of Network aware virtual migration techniques [7]}

\begin{tabular}{|c|c|c|}
\hline Type & $\begin{array}{l}\text { Why virtual machine } \\
\text { migration required? }\end{array}$ & $\begin{array}{c}\text { Performance } \\
\text { Metrics } \\
\end{array}$ \\
\hline $\begin{array}{c}\text { Network aware VM } \\
\text { Placement \& Migration } \\
\text { approach }\end{array}$ & $\begin{array}{l}\text { Due to unstable } \\
\text { network, data } \\
\text { transfer time crosses } \\
\text { the threshold value }\end{array}$ & $\begin{array}{c}\text { Time related } \\
\text { Service Level } \\
\text { Agreement(SLA) } \\
\text { between cloud } \\
\text { facility provider } \\
\text { and cloud user is } \\
\text { used to determine } \\
\text { the threshold } \\
\text { value }\end{array}$ \\
\hline $\begin{array}{c}\text { Traffic-aware VM } \\
\text { Placement Problem } \\
\text { (TVMPP) }\end{array}$ & $\begin{array}{l}\text { Virtual Machines on } \\
\text { host become greater } \\
\text { than the decided } \\
\text { number of hosts } \\
\end{array}$ & $\begin{array}{l}\text { Traffic pattern and } \\
\text { network topology } \\
\text { analysis in data } \\
\text { centers } \\
\end{array}$ \\
\hline $\begin{array}{c}\text { Optimization of data } \\
\text { center deployment \& VM } \\
\text { assignment }\end{array}$ & \begin{tabular}{|c|} 
Network latency \\
between clients and \\
data centers changes \\
drastically \\
\end{tabular} & $\begin{array}{l}\text { Scale solutions } \\
\text { based on } \\
\text { time(short/long) } \\
\text { are provided } \\
\end{array}$ \\
\hline $\begin{array}{c}\text { A Model-Based } \\
\text { Algorithm for Optimizing } \\
\text { I/O Intensive Applications } \\
\text { in Clouds } \\
\text { using VM-Based } \\
\text { Migration }\end{array}$ & $\begin{array}{l}\text { To minimize the } \\
\text { expected value of } \\
\text { time required to } \\
\text { access the file for } \\
\text { data intensive } \\
\text { application }\end{array}$ & $\begin{array}{l}\text { DAG shortest path } \\
\text { search problem }\end{array}$ \\
\hline $\begin{array}{l}\text { Network-aware migration } \\
\text { control and scheduling of } \\
\text { differentiated virtual } \\
\text { machine workloads }\end{array}$ & $\begin{array}{l}\text { To predict virtual } \\
\text { machine migration, } \\
\text { VM workload } \\
\text { classifier is used }\end{array}$ & \\
\hline $\begin{array}{c}\text { Network-Aware } \\
\text { Coordination of Virtual } \\
\text { Machine Migrations in } \\
\text { Enterprise Data Centers } \\
\text { and Clouds } \\
\end{array}$ & $\begin{array}{c}\text { Workload increased } \\
\text { in application due to } \\
\text { achievement of load } \\
\text { balancing and fault } \\
\text { tolerance } \\
\end{array}$ & $\begin{array}{l}\text { Link sharing and } \\
\text { software simulator } \\
\text { is used. }\end{array}$ \\
\hline
\end{tabular}




\section{International Journal of Science and Research (IJSR) \\ ISSN (Online): 2319-7064}

Index Copernicus Value (2013): 6.14 | Impact Factor (2014): 5.611

\section{Research Challenges in network based Live Virtual Machine Migration [4]}

1)Low Bandwidth over WAN: Due to large image size, it is impossible to trans-locate the live virtual machine across high latency low bandwidth WAN.

2)Network fault: In post copy, when Virtual machine at the target host tries to fetch the pages that have not yet transferred, it redirect towards the source host thus creates network faults as virtual machine at source host is suspended.

3)Memory intensive applications: to reduce the overhead of post copy technique than the overhead of memory reusing technique.

4)Memory state between clusters: live migration to have a control over transfer of CPU and memory state between cluster of hosts which serves as a single Virtual Distributed Shared Memory system.

\section{Current Challenges in Post copy Live Virtual Machine} Migration Technique:-

1)Firstly, there is challenge too reduce the overhead of Post copy technique than memory reusing technique. So that post copy technique can be optimized

2)Secondly, there is need to handle the transfer of CPU and memory state between cluster of hosts serving as a single Virtual Distributed Shared Memory system.

3)Thirdly, we need to plan to investigate an alternative to pseudo-paging, namely shadow paging based page fault detection, and to investigate techniques to handle target node failure during post copy migration, so that post copy can provide at least the same level of reliability as pre copy.

\section{Conclusion and Future Work}

The main objective of a cloud computing platform is to deliver efficient services to its clients. Its physical and logical infrastructure is known to consist of a large number of resources. In future work we have few research challenges in improvement of post copy virtual machine migration technique. Firstly, in future, we can make attempt to reduce the overhead of Post copy technique than memory reusing technique to prove it optimized. Secondly, there is need to handle the transfer of CPU and memory as a single Virtual Distributed Shared Memory system. Thirdly, we need to plan to find shadow paging based page fault detection, and to handle target node failure during post copy migration to make it reliable as pre copy. In the last we can say that there is less number of network aware migration technique available in virtual machine migration techniques of cloud environment.

\section{References}

[1] Rabiatul Addawiyah Mat Razali, Ruhani Ab Rahman, Norliza Zaini, Mustafa Samad, "Virtual Machine Migration Implementation in Load Balancing for Cloud Computing", in IEEE Conference, 2014

[2] Gursharan Singh, Sunny Behal, Monal Taneja, "Advanced Memory Reusing Mechanism for Virtual Machines in
Cloud Computing", 3rd International Conference on Recent Trends in Computing 2015 published by ELSEVIER, pp 91-103, July 2015

[3] Aidan Shribman, Benoit Hudzia, "Pre-Copy and Post-Copy VM Live Migration for Memory Intensive Applications", Springer, pp 539-547, 2013

[4] Divya Kapil, Emmanuel S.Pilli, Ramesh C.Joshi, "Live Virtual Machine Migration Techniques_Survey and Research Challenges", in IEEE, 2012

[5] Michael R.Hines, Umesh Deshpande, Kartik Gopalan, "Post-Copy Live Migration of Virtual Machines", availableat"httposnet.cs.binghamton.edupublicationshines0 9postcopy_osr.pdf”, 2009

[6] Michael R.Hines, Kartik Gopalan, "Post-Copy Based Live Virtual Machine Migration Using Adaptive Pre-Paging and Dynamic Self-Ballooning”, 2013

[7] Rinal M.Chawda, Ompriya Kale, "Virtual Machine Migration Techniques in Cloud Environment_A Survey", IJSRD, 2013

[8] Gulshan Soni, Mala Kalra, "Comparative Study of Live Virtual Machine Migration Techniques in Cloud", IJCA, vol 84, no. 14, December 2013

[9] Raja Wasim Ahmad, Abdullah Gani, Siti Hafizah Ab. Hamid, Muhammad Shiraz, Feng Xia, Sajjad A. Madani, "virtual machine migraton in cloud data centers_a review, taxonomy and open research issues", SPRINGER, 24732515, 2015

[10] Pradip D Patel, Miren Karamta, M.D.Bhavsar, M.B.Potdar, "Live Virtual Machine Migration Techniques in Cloud Computing A Survey”, IJCA, vol 86, no. 16, Jan 2014

[11] Soumya Ray, Ajanta De Sarkar, "Execution Analysis Of Load Balancing Algorithms In Cloud Computing Environment ", IJCCSA, vol 2, no. 5, Oct 2012

[12] Jaspreet Kaur, Manpreet Kaur, Sahil Vashist, "Virtual Machine Migration in Cloud Datacenters", IJARCSSE,vol 4, no. 8, pp 190-193,2014

[13] Raja Wasim Ahmad, Abdullah Gani, Siti Hafiza Ab. Hmid, Muhammad Shiraz, Abdullah Yousafzai, Feng Xia, "Journal of Network and Computer Applications", ELSEVIER, pp 11-25, 2015

[14] Qi Zhang, Lu Cheng, Raouf Boutaba, "Cloud computing: state-of-the-art and research challenges", published in IEEE and SPRINGER, April 2010

\section{Author Profile}

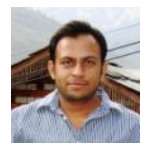

Rajwinder Singh received the M.Tech. degree in Computer Science \& Engineering stream from Lovely Professional University in 2010. His area of research is Cloud Computing \& Networking. He is currently pursuing Ph. D in Computer Sc \& Engineering from Guru Nanak Dev University, Amritsar.

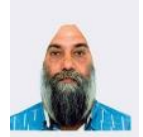

Dr. Karanjeet Singh Kahlon is academician having $\mathrm{M}$ Tech, $\mathrm{PhD}$ degree. His area of research is Networking \& Distributed Computing. He is currently working as Professor at Department of Computer Science, Guru Nanak Dev University, Amritsar.

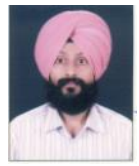

Mr. Sarabjit Singh is Post Graduate from Guru Nanak Dev University, Amritsar. He is currently working as System Manager at Guru Nanak Dev University, Amritsar. 